\title{
Effect of Reminder Tools on Drug Adherence among Patients on Anti- retroviral Drug in Specialist Hospital Yola, Adamawa State: A Randomized Field Trial
}

\author{
Jenewari, A.J ${ }^{*}$, Ogbeyi, O.G ${ }^{2}$, Igbinovia, I.F ${ }^{1}$ \\ ${ }^{I}$ Department of Public Health, Texila American University \\ ${ }^{2}$ Department of Epidemiology and Community Health, College of Health Sciences, Benue \\ State University, Makurdi, Nigeria
}

\begin{abstract}
A minimum of $95 \%$ drug adherence is necessary to achieve immunological and virological success in antiretroviral therapy, and to attain this level; patients need to be assisted. The study therefore aimed at comparing the effect of reminder tools on antiretroviral drug adherence among people living with human immunodeficiency virus. The study was a randomised field trial. Questionnaire and adherence assessment forms were administered to two hundred, and twenty-five patients, and information was elicited on socio-demographic history, antiretroviral drug usage, and adherence behaviour. Alarm clocks and counselling were given to one group, stickers, reminder cards, and counselling to the second group, while counselling alone was given to the third group as interventions. Three months later, data were collected from the same patients in order to compare the effect reminder tools had on antiretroviral drug adherence among the patients. Data were entered into Epi Info version 3.5.1 2008 statistical software and analyzed. The optimum adherence levels were $78.7 \%, 80.0 \%$, and $84.0 \%$ at pre-intervention among groups that had alarm clock with counselling, sticker, reminder card with counselling, and those that had counselling alone respectively. The drug side effect was negatively associated with adherence level ( $p<0.05$ ), while pill count was not associated with adherence level ( $p>0.05)$. At post-intervention, the adherence levels increased by $18.5 \%, 6.8 \%$, and $1.9 \%$, respectively, among groups that had alarm clock with counselling $(p<0.05)$, sticker, reminder card with counselling ( $p>0.05)$, and those that had counselling alone ( $p>0.05)$. The alarm clock was more effective than stickers and hand-held cards in improving adherence.
\end{abstract}

Keywords: Drug adherence, Patients, Retroviral drugs, Reminder tools, Specialist hospital, Yola.

\section{Introduction}

In recent years, advances in HIV therapeutics have changed the natural course of HIV/AIDS disease, such that it has assumed some of the characteristics of chronic diseases [1]. People on ARV drugs live much longer than those not on ARV drugs. Therefore, People living with HIV/AIDS need to know about antiretroviral medication in terms of its effectiveness. Those who currently have access to treatment need information about their treatment to enhance full adherence. Those without access also need information to become active in advocating for scale-up of drug coverage in their countries [2]. The World Health Organization (WHO) and UNAIDS estimated in 2005 that $72 \%$ of the unmet needs for HIV/AIDS treatment is in SSA and 22\% in Asia, with India, Nigeria, and South Africa accounting for $41 \%$ of the overall need for treatment worldwide [3].

Drug adherence may be defined as the extent to which a patient takes a medication in the way prescribed by the health provider. It has been proven to be the Achilles heel of antiretroviral 
therapy, but to achieve near-perfect adherence necessary for optimal ARV effect, the patient often requires some assistance [4]. The terms adherence and non-adherence are meant to be non-judgmental. They are statements of fact rather than expressions of judgment toward the patient or health care provider. Therefore, both patient and healthcare providers should work in partnership to achieve adherence to ARV medication [5]. Non-adherence with medications is a common problem and one that has been shown to adversely affect treatment outcomes. Increased mortality, development of drug resistance and consequent treatment failure, increased frequency of hospitalizations, and increased healthcare costs have all been associated with non-adherence.

The introduction of combination antiretroviral therapy or HAART has had a dramatic positive impact on the effectiveness of current HIV therapeutic strategies, with a subsequent decrease in mortality from the disease as well as a decline in opportunistic infections among HIV infected patients [6]. PLWHA need to take their drugs throughout their lives; therefore, long-term management of HIV/AIDS infection should include adherence preparation and support such as reminder tools, health education, and counselling [7, 8]. These reminder tools, alarm on clock, stickers, and hand cards are not expensive and can be easily inculcated into patient's care to maximize the effect on ARV adherence in low-resource settings. A study done on adherence among HIV patients has shown the association between poor adherence and ARV resistance; therefore, adherence measurement and support should be an integral part of ARV initiation to avoid drug resistance. Hence, the introduction of different reminder tools in this study to see the effect on adherence [9].

A minimum of $95 \%$ adherence is necessary to achieve virological success in patients receiving HAART [10]. Adherence may be improved using various methods. These include hand-held devices, a two-way pager, alarm medication vial along with social and emotional support, cue-dosing training, and monetary reinforcement [11]. Several studies elsewhere have shown alarm devices to improve adherence to medications [12, 13, 14]. Another study has shown the effectiveness of preprinted stickers in improving antibiotic prophylaxis among physicians [15]. This study aimed to compare the effect of different reminder tools and thereby to identify which method is better. Reasons for non-adherence are multi-factorial and differ from community to community [16]. This underscores the need for each treatment centre to look at the factors mitigating adherence and proffer solutions to reduce non-adherence.

Reminder tools are adherence aids that serve to remind the patient on medications for chronic illness. A variety of devices that may help patients adhere to their treatment regimens are available, including alarms on watches, stickers, reminder hand cards, beeps, and other electronic devices that allow for multiple daily reminders.

Due to the dearth of studies on the effect of reminder tools on adherence, this study will contribute to the existing scanty body of knowledge on adherence, factors affecting adherence, and feasible remedial actions that may help address poor adherence. Key findings from this study will provide the State Ministry of Health (SMOH), donor agencies, policy makers, and other stakeholders with valuable information on ways of improving ARV drug adherence and hence ensure the effectiveness of drug treatment and prevent the development of drug resistance. This has become important in the wake of renewed efforts to combat HIV/AIDS in Nigeria and end the HIV/AIDS pandemic.

\section{Methods}

The Specialist Hospital Yola, Adamawa State, Northeast Nigeria, was established in the late 1930s first as General Hospital Yola. In 1999 it was converted to a specialist hospital. 
The Hospital has a unit for HIV/AIDS treatment for people in Yola and its environs. It has regular antiretroviral and other supportive management for people living with HIV/AIDS (PLWHA). In all, about 4743 patients were on a free regular and uninterrupted supply of antiretroviral drugs at the Hospital supported by USAID with Chemonics leading Task orders 2 and 3 .

Yola is the capital city of Adamawa State in Northeast Nigeria. It is centrally located within the State, and has a population of 392, 854 [17]. Yola is located on the Benue River, on latitude $9^{\circ} 12^{\prime} 0^{\prime \prime} \mathrm{N}$ and longitude $12^{\circ} 29^{\prime} 0^{\prime \prime} \mathrm{E}$, with daytime temperatures easily exceeding $40^{\circ} \mathrm{C}$ during the dry season (March/April) [18]. The indigenous ethnic group is Fulani. Other ethnic groups such as Hausa, Igbo, and Yoruba have also come to settle in Yola Local Government Area (LGA). The main religions practiced are Christianity, Islam, and Traditional worship. The inhabitants are mostly civil servants and traders. It has two tertiary health centers; Specialist Hospital Yola and Federal Medical Centre Yola, and 43 primary health care facilities. Yola has six tertiary institutions.

\section{Study Population}

The study population consisted of 4743 PLWHA attending Specialist Hospital Yola and receiving antiretroviral drugs. All adult PLWHA.

( $\geq 1$ 8years) attending Specialist Hospital Yola for ARV therapy for not less than 6 months was included in the study. The following were excluded from the study, newly diagnosed HIV/AIDS patients; patients who were unwilling to participate; those on treatment for less than 6 months, and on oncedaily doses.

\section{Study Design}

The study was a randomised controlled field trial to compare the effect of an alarm clock, sticker, and reminder card with counselling on ARV drug adherence among PLWHA in
Specialist Hospital Yola. Respondents were randomised into Group A (alarm clock and counselling only), Group B (sticker, reminder card and counselling only) and Group C (counselling only) using a simple random sampling technique by balloting. The study was carried out in three phases; A pre-intervention, an intervention, and a post-intervention phase.

At the pre-intervention phase, baseline data were collected using an intervieweradministered questionnaire and an adherence assessment form. After this, respondents were then given appointments to come for the administration of interventions. Respondents in groups A and B were administered interventions on the last Thursday and Tuesday of the month, respectively, while those in group $\mathrm{C}$ were asked to come on Thursday of the first week of the month for counselling alone. The interventions were administered at the ART counselling room within the hospital premises. On each clinic day, the 75 respondents in each group were divided into three groups of twentyfive each for a follow-up adherence counselling which was given in groups by the adherence nurses and the researcher. The counselling lasted for about 30 minutes, after which reminder tools were given to each respondent with the exception of those in group $\mathrm{C}$ that had only adherence counselling.

A portable alarm clock was given to each respondent in group A. The clock was a 12hourly alarm clock which fits into the regular drug timing because respondents were on the twice daily dosage of ARV drugs (usually 8am and $8 \mathrm{pm}$ or $7 \mathrm{am}$ and $7 \mathrm{pm}$ ). They were told to carry the alarm clock in their bags or place them at home close to their drugs. Those in this group who had cell phones were asked to set their cell phones on alarm as a reminder when not at home. Extra batteries were given to them, and they were told to report any malfunctioning of the clock to the research team for immediate replacement.

The respondents who had stickers were told to paste the stickers at strategic places, i.e., 
behind the bedroom door, bedroom mirror, and beside the bed, among other locations within the house during the counselling. The stickers had an inscription "DON'T MISS YOUR DRUG: IT IS TIME TO TAKE YOUR DRUG" with a pictorial component that served as a visual reminder. The sticker was translated into local language for those who did not understand the English language. The sticker was pretested at the General Hospital Numan among different sexes and ages of PLWHA before use. A total of three stickers were given to each respondent. An inquiry was made about the stickers at every visit to ensure proper use. Reminder hand cards adopted from the Institute of Human Virology in Nigeria (IHVN) were given to those with stickers to remind them about taking their drugs when away from home [19]. They were asked to put the hand card in their wallet, handbag, and pocket wherever they go and to report any damage to it for immediate replacement. All respondents were asked to come along with the alarm clocks and the reminder cards at every visit. The administration of intervention was done by the researcher and the three adherence nurses. Alarm clocks, stickers, and reminder cards were all provided by the researcher to all the respondents free of charge.

Each group was given a monthly appointment for follow-up visits for a period of three months. At each visit, they were given counselling preceding the collection of drugs. The counselling was a follow-up group counselling of 25 per group. The group counselling was centered on reminder tool usage and difficulties in drug medications. It was done in the ARV counselling room lasting for 30-45 minutes per group.

\section{Sample Size Determination}

Sample size formulae for comparison of proportions were used to calculate sample size [20].

$\mathrm{n}_{\mathrm{a}}=\frac{\left[\mathrm{Z}_{\alpha} \sqrt{2}(\mathrm{P})(1-\mathrm{P})+\mathrm{Z}_{\beta} \sqrt{\left.\mathrm{P}_{1}\left(1-\mathrm{P}_{1}\right)+\mathrm{P}_{2}\left(1-\mathrm{P}_{2}\right)\right]^{2}}\right.}{(\mathrm{P} 2-\mathrm{P} 1)^{2}}$

$$
\begin{aligned}
& \mathrm{n}=\mathrm{n}_{\mathrm{a}} / 4\left[1+\sqrt{1}+4 / \mathrm{n}_{\mathrm{a}}\left(\mathrm{P}_{1}-\mathrm{P}_{2}\right)\right]^{2} \\
& \mathrm{n}_{\mathrm{a}}=\text { Minimum sample size } \\
& \mathrm{n}=\text { Minimum sample size with } \\
& \text { continuity correction } \\
& \mathrm{Z}_{\alpha}=\text { Standard normal deviate } \\
& \text { corresponding to confidence level; } \\
& \text { at } 95 \% \text { confidence level, } \mathrm{Z}_{\alpha}=1.96 \\
& Z_{\beta}=\text { Standard normal deviate } \\
& \text { corresponding to Power of study; at } \\
& 80 \%, Z_{\beta}=0.84 \\
& \mathrm{P}_{1}=\text { Proportion of optimum adherence in } \\
& \text { a group at baseline }=0.851 \mathrm{In} \text { a } \\
& \text { prospective study among } 130 \mathrm{HIV} \\
& \text { positive patients in Jos to determine } \\
& \text { ARV adherence level, } 85.1 \% \text { of } \\
& \text { them had optimum adherence [21]. } \\
& \mathrm{P}_{2}=\text { Proportion of expected optimum } \\
& \text { adherence in a group after } \\
& \text { intervention }\left(\mathrm{P}_{2}\right)=0.991[22] \text {. } \\
& \mathrm{P}=\mathrm{P}_{1}+\mathrm{P}_{2} / 2=0.921 \\
& \mathrm{n}=71
\end{aligned}
$$

With the addition of a 5\% attrition rate, a sample size of 75 was calculated.

Therefore 75 respondents were used per group, giving a total of 225 respondents in the study.

\section{Sampling Method}

The study respondents were selected using a simple random sampling technique. After purposively selecting the Specialist Hospital Yola, a sampling frame was obtained using the register of all eligible clients on antiretroviral drugs attending the hospital. Two hundred and twenty-five respondents were selected by simple random sampling technique using computer-generated random numbers from a frame of eligible 4743 clients.

\section{Randomization}

The two hundred and twenty-five (225) respondents selected were randomised into the three groups (A, B, and C) using a simple random sampling technique by balloting. Numbers between 1 to 9 were written on pieces of paper of some size and rapped before being 
put into a box. Each of the numbers had 25 rappers totalling 225 rappers in the box. Patients who picked numbers 1 to 3 were allocated to group A, those who picked numbers 4 to 6 were allocated to group B and those who picked numbers 7 to 9 were allocated to group C. This resulted in equal randomization of 75 respondents to each of the groups.

\section{Data Collection Instrument}

A semi-structured, interviewer-administered questionnaire, adapted from harmonised medication assessment adherence questionnaire by GHAIN, was used in the collection of data in the study. The questionnaire had two sections A and B. Section A elicited information on socio-demographic characteristics, and section B on HIV infection history, antiretroviral drug usage, and adherence behaviour. An adherence assessment form was used to measure the adherence level of the respondents in all three groups. Adherence was measured as a percentage of doses taken out of the total expected over a 4-day period. The questionnaire was pre-tested at General Hospital Numan, where it was administered to 25 PLWHA. This help in detecting difficulties in the questionnaire, and corrections were made.

\section{Preparation for Data Collection}

The study was conducted between July and November 2020. Three adherence counsellors (nurses) that had been trained and retrained on adherence counselling by GHAIN were trained for data collection. The adherence counsellors had a 1-day refresher training session in the ARV counselling room within the hospital premises. The refresher training was on the overview of the research, including the aims and objectives, a recap of counselling techniques specifically follows up counselling and the use of research instruments during the study. The training lasted for 2 hours and was given by the researcher. This was to ensure quality, uniformity, and standardization in data collection.

\section{Data Collection Technique}

\section{Pre-intervention Data Collection}

Pre-intervention data collection was done over a period of four weeks, during the two clinic days that ran on Tuesdays and Thursdays. After the selection of respondents from the register, the research team sat on each of the clinic days awaiting respondents. As selected respondents were seen on the clinic days, the research team introduced themselves to the respondents, explained the purpose of the research, and were assured of the confidentiality of all information given by them, after which written informed consent was sought and obtained from each respondent before being recruited into the study. On that same day, the questionnaire and adherence assessment form were administered for baseline data collection from the respondents. At the end of each day's data collection exercise, the researcher collected the questionnaire and manually cross-checked them for data entry errors, missing values, and inconsistencies.

\section{Post-intervention Data Collection}

At the end of 3 months after the intervention, for each respondent, the same questionnaire that was used at baseline was administered, and the adherence level was measured for each respondent in all three groups.

\section{Data Processing and Analysis}

All data generated at baseline and postintervention were processed and analysed using Epi Info version 3.5.1 (2008) statistical software. Frequency tables were generated for the socio-demographic data, and categorical data were presented as frequencies and percentages, while continuous data were described using mean and standard deviation as appropriate. Pearson's Chi-square $\left(\chi^{2}\right)$ or Likelihood ratio Chi-square $\left(\mathrm{G}^{2}\right)$ test for small sample comparisons were used to test for the 
statistical relationship between factors influencing ARV drug adherence within groups. McNemar's Chi-square $\left(\chi^{2}\right)$ was used to compare adherence between groups before and after the intervention. At $95 \%$ confidence level, a p-value of less than 0.05 was considered statistically significant. The outcome variable measured in this study was adherence level. At pre-and post-intervention, the level of adherence was measured for respondents in all the three groups by a 4-day self-reported assessment using adherence assessment form.[23].

Adherence level $=\frac{\text { No of doses taken } \times 100}{\text { Expected no of doses }}$

Adherence levels were categorised as follows:

Optimum adherence $\geq 95 \%$

Sub-Optimum adherence 80\% -94\%

Poor adherence $<80 \%$.

\section{Ethical Consideration}

Ethical clearance was sought and obtained from the Jos University Teaching Hospital (JUTH) Research and Ethics Committee. Written permission was obtained from the authority of Specialist Hospital Yola. Written informed consent was obtained from all respondents. Participation was voluntary, and they were given the option to opt-out of the study if they so wished, with the understanding that the refusal of participation would not attract any punishment or denial of benefit.

\section{Limitation of the Study}

Some respondents may not give their true report of non-adherent behaviours, since adherence was measured by self-report; this will result in information bias, thereby overreporting adherence. This was minimised by non-judgemental counselling.

Results

Table 1. Socio-demographic Characteristics of PLWHA* at Specialist Hospital Yola

\begin{tabular}{|c|c|c|c|c|c|c|}
\hline \multirow{3}{*}{ Characteristics } & \multirow{2}{*}{\begin{tabular}{|l|} 
Study group A \\
$(n=75)$ \\
\end{tabular}} & \multirow{2}{*}{$\begin{array}{l}\text { Study group B } \\
(n=75)\end{array}$} & \multirow{2}{*}{$\begin{array}{l}\text { Control group } C \\
(n=75)\end{array}$} & Total & \multirow[t]{3}{*}{ Test statistics } & \multirow[t]{3}{*}{ P-Value } \\
\hline & & & & \multirow[t]{2}{*}{ Freq $(\%)$} & & \\
\hline & Freq $(\%)$ & Freq $(\%)$ & Freq $(\%)$ & & & \\
\hline \multicolumn{7}{|c|}{ Age Groups(yrs) } \\
\hline$<30$ & $27(33.3)$ & $31(38.3)$ & $23(28.4)$ & $81(100)$ & \multirow[t]{4}{*}{$\chi^{2}=6.633$} & \multirow[t]{4}{*}{0.356} \\
\hline $30-39$ & $29(34.9)$ & $26(31.4)$ & $28(33.7)$ & $83(100)$ & & \\
\hline $40-49$ & $10(23.2)$ & $15(34.9)$ & $18(41.9)$ & $43(100)$ & & \\
\hline$\geq 50$ & $9(50.0)$ & $3(16.7)$ & $6(33.3)$ & $18(100)$ & & \\
\hline \multicolumn{7}{|l|}{ Sex } \\
\hline Male & $27(38.6)$ & $21(30.0)$ & $22(31.4)$ & $70(100)$ & \multirow[t]{2}{*}{$\chi 2=1.286$} & \multirow[t]{2}{*}{0.526} \\
\hline Female & $48(31.0)$ & $54(34.8)$ & $53(34.2)$ & $155(100)$ & & \\
\hline \multicolumn{7}{|l|}{ Marital Status } \\
\hline Single & $16(40.0)$ & $12(30.0)$ & $12(30.0)$ & $40(100)$ & \multirow[t]{5}{*}{$\mathrm{G}^{2}=7.541$} & \multirow[t]{5}{*}{0.480} \\
\hline Cohabiting & $1(16.7)$ & $4(66.6)$ & $1(16.7)$ & $6(100)$ & & \\
\hline Married & $45(36.6)$ & $38(30.9)$ & $40(32.5)$ & $123(100)$ & & \\
\hline Divorced & $7(28.0)$ & $9(36.0)$ & $9(36.0)$ & $25(100)$ & & \\
\hline Widowed & $6(19.4)$ & $12(38.7)$ & $13(41.9)$ & $31(100)$ & & \\
\hline \multicolumn{7}{|c|}{ Level of Education } \\
\hline No Education & $16(32.7)$ & $18(36.7)$ & $15(30.6)$ & $49(100)$ & \multirow[t]{4}{*}{$\chi^{2}=2.707$} & \multirow[t]{4}{*}{0.845} \\
\hline Primary & $14(28.0)$ & $20(40.0)$ & $16(32.0)$ & $50(100)$ & & \\
\hline Secondary & $27(33.8)$ & $24(30.0)$ & $29(36.2)$ & $80(100)$ & & \\
\hline Tertiary & $18(39.1)$ & $13(28.3)$ & $15(32.6)$ & $46(100)$ & & \\
\hline
\end{tabular}




\begin{tabular}{|c|c|c|c|c|c|c|}
\hline \multicolumn{7}{|l|}{ Religion } \\
\hline Christianity & $40(36.7)$ & 37 (33.9) & $32(29.4)$ & $109(100)$ & \multirow[t]{2}{*}{$\chi 2=1.744$} & \multirow[t]{2}{*}{0.418} \\
\hline Islam & $35(30.2)$ & $38(32.7)$ & $43(37.1)$ & $116(100)$ & & \\
\hline \multicolumn{7}{|l|}{ Occupation } \\
\hline Applicant & $7(28.0)$ & $5(20.0)$ & $13(52.0)$ & $25(100)$ & \multirow[t]{7}{*}{$\mathrm{G}^{2}=17.667$} & \multirow[t]{7}{*}{0.126} \\
\hline Artisan & $6(28.6)$ & $7(33.3)$ & $8(38.1)$ & 21(100) & & \\
\hline Civil servant & $18(34.6)$ & 14(26.9) & $20(38.5)$ & $52(100)$ & & \\
\hline Farmer & $5(38.5)$ & $7(53.8)$ & $1(7.7)$ & $13(100)$ & & \\
\hline Housewife & $17(32.1)$ & $17(32.1)$ & $19(35.8)$ & $53(100)$ & & \\
\hline Student & $3(60.0)$ & $2(40.0)$ & $0(0.0)$ & $5(100)$ & & \\
\hline trader & 19(33.9) & $23(41.1)$ & $14(25.0)$ & $56(100)$ & & \\
\hline
\end{tabular}

There were about the same proportions of respondents in the age group 30-39 years (A $34.9 \%$; B $31.4 \%$; C $33.7 \%$ ) in all the groups. The distributions of female respondents in the study groups were similar $(\mathrm{p}=0.526)$, while the distributions of married respondents were $36.6 \%, 30.9 \%$, and $32.5 \%$ in groups $\mathrm{A}, \mathrm{B}$, and $\mathrm{C}$, respectively. About $33.8 \%, 30.0 \%$, and $36.3 \%$ of respondents who had secondary education were in groups A, B, and C, respectively. The distributions of respondents that were Christians were $36.7 \%, 33.9 \%$, and $29.4 \%$ in groups $\mathrm{A}, \mathrm{B}$, and $\mathrm{C}$, respectively, while the distributions of civil servants among respondents were $34.6 \%, 26.9 \%$, and $38.5 \%$ in groups $\mathrm{A}, \mathrm{B}$, and $\mathrm{C}$ respectively. The study groups were similar with respect to all sociodemographic characteristics measured (Table $1)$.

Table 2. Time of Diagnosis of HIV Infection among PLWHA at Specialist Hospital Yola

\begin{tabular}{|l|l|l|l|}
\hline \multirow{2}{*}{ Time (yrs) } & Study A & Study B & Control C \\
\cline { 2 - 4 } & Freq (\%) & Freq (\%) & Freq (\%) \\
\hline$<2$ & $18(24.0)$ & $25(33.3)$ & $24(32.0)$ \\
\hline $2-3$ & $45(60.0)$ & $36(48.3)$ & $41(54.7)$ \\
\hline $4-5$ & $10(13.3)$ & $13(17.3)$ & $9(12.0)$ \\
\hline$\geq 6$ & $2(2.7)$ & $1(1.3)$ & $1(1.3)$ \\
\hline Total & $75(100)$ & $75(100)$ & $75(100)$ \\
\hline
\end{tabular}

$\mathrm{G}^{2}=3.601 ; \mathrm{df}=6 ; \mathrm{p}=0.731$

A majority of respondents in all groups had lived with HIV for between 2-3yrs $(60 \%$ in group A, $48.3 \%$ in group B, and $54.7 \%$ in group
C). The groups did not differ significantly in the number of years respondents had lived with HIV ( $\mathrm{p}=0.731)$ (Table 2).

Table 3. Duration of ARV use among PLWA at the Specialist Hospital Yola

\begin{tabular}{|l|l|l|l|}
\hline \multirow{2}{*}{ Duration (yrs) } & Study A & Study B & Control C \\
\cline { 2 - 4 } & Freq (\%) & Freq (\%) & Freq (\%) \\
\hline$<2$ & $22(29.3)$ & $32(42.7)$ & $31(41.3)$ \\
\hline $2-3$ & $47(62.7)$ & $36(48.0)$ & $40(53.3)$ \\
\hline $4-5$ & $4(5.3)$ & $6(8.0)$ & $3(4.0)$ \\
\hline$\geq 6$ & $2(2.7)$ & $1(1.3)$ & $1(1.3)$ \\
\hline Total & $75(100)$ & $75(100)$ & $75(100)$ \\
\hline
\end{tabular}

$\mathrm{G}^{2}=5.262 ; \mathrm{df}=6 ; \mathrm{p}=0.515$ 
A majority of respondents in all groups had used ARV for between 2-3yrs $(62.7 \%$ in group A, $48.0 \%$ in group B, and $53.3 \%$ in group C).
The groups did not differ significantly in the duration of ARV use by respondents $(\mathrm{p}=0.515)$ (Table 3).

Table 4. Number of Pills per Dose of ARVS Taken by PLWHA by Study Group, Pre-intervention, Specialist Hospital Yola

\begin{tabular}{|l|l|l|l|}
\hline \multirow{2}{*}{$\begin{array}{l}\text { No of Pills } \\
\text { per Dose }\end{array}$} & Study A & Study B & Control C \\
\cline { 2 - 4 } & Freq (\%) & Freq (\%) & Freq (\%) \\
\hline 1 & $25(33.3)$ & $19(25.3)$ & $17(22.7)$ \\
\hline 2 & $50(66.7)$ & $56(74.7)$ & $58(77.3)$ \\
\hline Total & $75(100)$ & $75(100)$ & $75(100)$ \\
\hline
\end{tabular}

$\chi^{2}=2.339 ; \mathrm{df}=2 ; \mathrm{p}=0.311$

A majority of the respondents in all groups used 2 pills per dose $(66.7 \%$ in group A, $74.7 \%$ in group $\mathrm{B}$, and $77.3 \%$ in group $\mathrm{C})$. The groups did not differ significantly in the number of pills per dose used by respondents $(\mathrm{p}=0.311)$. (Table 4).

Table 5. Prevalence of ARV Side Effects among PLWHA by Study group Pre-intervention, Specialist Hospital Yola

\begin{tabular}{|l|l|l|l|}
\hline \multirow{2}{*}{ Side Effect } & Study A & Study B & Control C \\
\cline { 2 - 4 } & Freq (\%) & Freq (\%) & Freq (\%) \\
\hline Present & $19(25.3)$ & $21(28.0)$ & $13(17.3)$ \\
\hline Absent & $56(74.7)$ & $54(72.0)$ & $62(82.7)$ \\
\hline Total & $75(100)$ & $75(100)$ & $75(100)$ \\
\hline
\end{tabular}

$\chi^{2}=2.567 ; \mathrm{df}=2 ; \mathrm{p}=0.277$

Most of the respondents, $74.7 \%$ in group A, $72.0 \%$ in group $\mathrm{B}$, and $82.7 \%$ in $\mathrm{C}$, reported the absence of side effects; however, only $25.3 \%$, $28.0 \%$, and $17.3 \%$ of the respondents reported side effect in groups $\mathrm{A}, \mathrm{B}$, and $\mathrm{C}$ respectively. The groups did not differ significantly in the prevalence of side effects among respondents in the groups $(\mathrm{p}=0.277)$ (Table 5).

Table 6. Reasons for Missed Doses of ARVS among PLWHA Pre-intervention, Specialist Hospital, Yola

\begin{tabular}{|l|l|l|l|}
\hline \multirow{2}{*}{ Reasons for Missed Doses } & Study A & Study B & Control C \\
\cline { 2 - 4 } & Freq (\%) & Freq (\%) & Freq (\%) \\
\hline Abnormal feeling/side effect & $19(25.3)$ & $21(28.0)$ & $13(17.3)$ \\
\hline Ashamed of taking drugs outside home & $2(2.7)$ & $3(4.0)$ & $3(4.0)$ \\
\hline Feeling better & $3(4.0)$ & $6(8.0)$ & $4(5.3)$ \\
\hline Feeling of depression & $1(1.3)$ & $3(4.0)$ & $0(0.0)$ \\
\hline Forgot to take drugs & $50(66.7)$ & $42(56.0)$ & $55(73.3)$ \\
\hline Total & $75(100)$ & $75(100)$ & $75(100)$ \\
\hline
\end{tabular}

The common reason stated by respondents in all the groups for missing drug doses was forgetfulness (A $66.7 \%$; B 56.0\%; C 73.3\%), while a feeling of been depressed was the least reason for missing drug doses (A 1.3\%; B $4.0 \%$; C 0.0\%) (Table 6). 
Table 7. Assessment of Adherence Level among PLWHA Pre-intervention, Specialist Hospital Yola

\begin{tabular}{|l|l|l|l|}
\hline \multirow{2}{*}{ Adherence Level } & Study A & Study B & Control C \\
\cline { 2 - 4 } & Freq (\%) & Freq (\%) & Freq (\%) \\
\hline Optimum & $59(78.7)$ & $60(80.0)$ & $63(84.0)$ \\
\hline Sub-optimum & $13(17.3)$ & $11(14.7)$ & $7(9.3)$ \\
\hline Poor & $3(4.0)$ & $4(5.3)$ & $5(6.7)$ \\
\hline Total & $75(100)$ & $75(100)$ & $75(100)$ \\
\hline
\end{tabular}

$\mathrm{G}^{2}=2.539 ; \mathrm{df}=4 ; \mathrm{p}=0.638$

Respondents in groups $\mathrm{A}, \mathrm{B}$, and $\mathrm{C}$ reported optimum adherence of $78.7 \%, 80.0 \%$, and $84.0 \%$, respectively, while only $4.0 \%$ in group $\mathrm{A}, 5.3 \%$ in group $\mathrm{B}$, and $6.7 \%$ in group $\mathrm{C}$ reported poor drug adherence. There was no significant difference in adherence level between the groups $(\mathrm{p}=0.638)$ at preintervention (Table 7).

Table 8. Relationship Between Presence of Side Effects and Adherence Level of PLWHA by Study Group, Preintervention, Specialist Hospital Yola

\begin{tabular}{|c|c|c|c|c|c|c|}
\hline \multirow{2}{*}{$\begin{array}{l}\text { Group/ } \\
\text { Adherence Level }\end{array}$} & \multicolumn{3}{|c|}{ Side Effect } & \multirow[t]{2}{*}{$G^{2}$} & \multirow[t]{2}{*}{ df } & \multirow[t]{2}{*}{ p-value } \\
\hline & Present & Absent & Total & & & \\
\hline \multicolumn{7}{|l|}{ Group A } \\
\hline Poor & $1(5.3)$ & $1(1.9)$ & $2(2.7)$ & \multirow[t]{4}{*}{20.693} & \multirow[t]{4}{*}{2} & \multirow[t]{4}{*}{0.001} \\
\hline Sub-optimal & $10(52.6)$ & $4(7.1)$ & $14(18.7)$ & & & \\
\hline Optimal & $8(42.1)$ & $51(91.0)$ & $59(78.6)$ & & & \\
\hline Total & $19(100)$ & $56(100)$ & $75(100)$ & & & \\
\hline \multicolumn{7}{|l|}{ Group B } \\
\hline Poor & $2(9.5)$ & $3(5.6)$ & $5(6.7)$ & \multirow[t]{4}{*}{6.034} & \multirow[t]{4}{*}{2} & \multirow[t]{4}{*}{0.049} \\
\hline Sub-optimal & $6(28.6)$ & $4(7.4)$ & $10(13.3)$ & & & \\
\hline Optimal & $13(61.9)$ & $47(87.0)$ & $60(80.0)$ & & & \\
\hline Total & $21(100)$ & $54(100)$ & $75(100)$ & & & \\
\hline \multicolumn{7}{|l|}{ Group C } \\
\hline Poor & $1(7.7)$ & $2(3.2)$ & $3(4.0)$ & \multirow[t]{4}{*}{6.097} & \multirow[t]{4}{*}{2} & \multirow[t]{4}{*}{0.047} \\
\hline Sub-optimal & $4(30.8)$ & $5(8.1)$ & $9(12.0)$ & & & \\
\hline Optimal & $8(61.5)$ & $55(88.7)$ & $63(84.0)$ & & & \\
\hline Total & $13(100)$ & $62(100)$ & $75(100)$ & & & \\
\hline
\end{tabular}

Table 9. Relationship Between Presence of Side Effects and Adherence Level of PLWHA by Study Group, Post-intervention, Specialist Hospital Yola

\begin{tabular}{|l|l|l|l|l|l|l|}
\hline \multirow{2}{*}{$\begin{array}{l}\text { Group/ } \\
\text { Adherence Level }\end{array}$} & \multicolumn{2}{|l|}{ Side Effect } & \multirow{2}{*}{ S $^{2}$} & df & p-value \\
\cline { 2 - 4 } Group A & Present & Absent & Total & & & \\
\hline Poor & $0(0.0)$ & $0(0.0)$ & $0(0.0)$ & 6.498 & 1 & 0.011 \\
\hline Sub-optimal & $2(13.3)$ & $0(0.0)$ & $2(2.8)$ & & & \\
\hline Optimal & $13(86.7)$ & $57(100)$ & $70(97.2)$ & & & \\
\hline Total & $15(100)$ & $57(100)$ & $72(100)$ & & & \\
\hline Group B & $0(0.0)$ & $0(0.0)$ & $0(0.0)$ & 12.302 & 1 & 0.001 \\
\hline Poor
\end{tabular}




\begin{tabular}{|c|c|c|c|c|c|c|}
\hline Sub-optimal & $7(38.9)$ & $2(4.0)$ & $9(13.2)$ & & & \\
\hline Optimal & $11(61.1)$ & $48(96$. & $59(86.8)$ & & & \\
\hline Total & $18(100)$ & $50(100)$ & $68(100)$ & & & \\
\hline \multicolumn{7}{|l|}{ Group C } \\
\hline Poor & $1(9.1)$ & $0(0.0)$ & $1(1.4)$ & \multirow[t]{4}{*}{6.295} & \multirow[t]{4}{*}{2} & \multirow[t]{4}{*}{0.043} \\
\hline Sub-optimal & $3(27.3)$ & $6(10.0)$ & $9(12.7)$ & & & \\
\hline Optimal & $7(63.6)$ & $54(90.0)$ & $61(85.9)$ & & & \\
\hline Total & 11(100) & $60(100)$ & $71(100$ & & & \\
\hline
\end{tabular}

Clients who did not report side effects of $(p=0.001)$, group $B(p=0.049)$, group $\mathrm{C}$ ARVs were significantly more likely to have $\quad(p=0.047)$ pre=intervention, and at postoptimal adherence compared with those who intervention group $\mathrm{A}(\mathrm{p}=0.011)$, group $\mathrm{B}$ reported side effects in all groups, group A $\quad(p=0.001)$, group $C(p=0.043)$ (Table $8 \& 9)$.

Table 10. Relationship Between Number of Pills per Dose of ARV Drug and Adherence Level of PLWHA by Study Group, Pre-intervention, Specialist Hospital Yola

\begin{tabular}{|c|c|c|c|c|c|c|}
\hline \multirow{2}{*}{$\begin{array}{l}\text { Group/ } \\
\text { Adherence Level }\end{array}$} & \multicolumn{3}{|c|}{ No of Pills per Dose } & \multirow[t]{2}{*}{$G^{2}$} & \multirow[t]{2}{*}{ df } & \multirow[t]{2}{*}{ p-value } \\
\hline & 1 & 2 & Total & & & \\
\hline \multicolumn{7}{|l|}{ Group A } \\
\hline Poor & $0(0.0)$ & $3(6.0)$ & $3(4.0)$ & \multirow[t]{4}{*}{3.496} & \multirow[t]{4}{*}{2} & \multirow[t]{4}{*}{0.174} \\
\hline Sub-optimal & $3(12.0)$ & $10(20.0)$ & $13(17.3)$ & & & \\
\hline Optimal & $22(88.0)$ & $37(74.0)$ & $59(78.7)$ & & & \\
\hline Total & $25(100)$ & $50(100)$ & $75(100)$ & & & \\
\hline \multicolumn{7}{|l|}{ Group B } \\
\hline Poor & $1(5.3)$ & $3(5.2)$ & $4(5.3)$ & \multirow[t]{4}{*}{2.166} & \multirow[t]{4}{*}{2} & \multirow[t]{4}{*}{0.339} \\
\hline Sub-optimal & $1(5.3)$ & $10(17.9)$ & $11(14.7)$ & & & \\
\hline Optimal & $17(89.4)$ & $43(76.9)$ & $60(80.0)$ & & & \\
\hline Total & $19(100)$ & $56(100)$ & $75(100)$ & & & \\
\hline \multicolumn{7}{|l|}{ Group C } \\
\hline Poor & $3(17.6)$ & $2(3.5)$ & $5(6.7)$ & \multirow[t]{4}{*}{3.826} & \multirow[t]{4}{*}{2} & \multirow[t]{4}{*}{0.148} \\
\hline Sub-optimal & $2(11.8)$ & $5(8.6)$ & $7(9.3)$ & & & \\
\hline Optimal & $12(70.6)$ & $51(87.9)$ & $63(84.0)$ & & & \\
\hline Total & $17(100)$ & $58(100)$ & $75(100)$ & & & \\
\hline
\end{tabular}

Table 11. Relationship Between Number of Pills per Dose of ARV Drug and Adherence Level of PLWHA by Study Group, Post-intervention, Specialist Hospital Yola

\begin{tabular}{|l|l|l|l|l|l|l|}
\hline \multirow{2}{*}{$\begin{array}{l}\text { Group/ } \\
\text { Adherence Level }\end{array}$} & \multicolumn{3}{|l|}{ No of Pills per Dose } & \multirow{2}{*}{ G $^{2}$} & df & p-value \\
\cline { 2 - 4 } & $\mathbf{1}$ & $\mathbf{2}$ & Total & & & \\
\hline Group A & $0(0.0)$ & $0(0.0)$ & $0(0.0)$ & 0.243 & 1 & 0.622 \\
\hline Poor & $1(4.2)$ & $1(2.1)$ & $2(2.8)$ & & & \\
\hline Sub-optimal & $23(95.8)$ & $47(97.9)$ & $70(97.2)$ & & & \\
\hline Optimal & $24(100)$ & $48(100)$ & $72(100)$ & & & \\
\hline Total & $0(0.0)$ & $0(0.0)$ & $0(0.0)$ & 0.044 & 1 & 0.838 \\
\hline Group B & $2(13.3)$ & $7(15.9)$ & $9(13.2)$ & & & \\
\hline Poor &
\end{tabular}




\begin{tabular}{|c|c|c|c|c|c|c|}
\hline Optimal & $15(86.7)$ & $44(84.1)$ & $59(86.8)$ & & & \\
\hline Total & $17(100)$ & $51(100)$ & $68(100)$ & & & \\
\hline \multicolumn{7}{|l|}{ Group C } \\
\hline Poor & $1(7.1)$ & $0(0.0)$ & $1(1.4)$ & \multirow[t]{4}{*}{3.690} & \multirow[t]{4}{*}{2} & \multirow[t]{4}{*}{0.158} \\
\hline Sub-optimal & $2(14.3)$ & $7(12.3)$ & $9(12.7)$ & & & \\
\hline Optimal & 11(78.6) & $50(87.7)$ & $61(85.9)$ & & & \\
\hline Total & $14(100)$ & $57(100)$ & $71(100)$ & & & \\
\hline
\end{tabular}

The number of pills per dose had no $(p=0.339)$ and $C(p=0.148)$ and at postassociation with adherence level in all group's pre-intervention, group A $(\mathrm{p}=0.174)$, group $\mathrm{B}$ intervention. A $(\mathrm{p}=0.622)$, group $\mathrm{B}(\mathrm{p}=0.838)$ and $\mathrm{C}(\mathrm{p}=0.158)$. (Table 10\&11).

Table 12. Comparison of Adherence Level Between Groups A and B Pre-intervention, Specialist Hospital Yola

\begin{tabular}{|l|l|l|}
\hline \multirow{2}{*}{ Adherence level } & Group A & Group B \\
\cline { 2 - 3 } & freq (\%) & freq (\%) \\
\hline Optimum & $59(78.7)$ & $60(80.0)$ \\
\hline Sub-optimum & $13(17.3)$ & $11(14.7)$ \\
\hline Poor & $3(4.0)$ & $4(5.3)$ \\
\hline Total & $75(100)$ & $75(100)$ \\
\hline
\end{tabular}

$\mathrm{G}^{2}=0.318 ; \mathrm{df}=2 ; \mathrm{p}=0.853$

A majority of the respondents, $78.7 \%$ and $80.0 \%$ in groups $\mathrm{A}$ and $\mathrm{B}$, respectively had optimum adherence. The adherence levels of

respondents did not differ significantly between the two groups pre-intervention $(\mathrm{p}=0.853)$ (Table 12).

Table 13. Comparison of Adherence Level Pre- and Post-intervention by Study Group, Specialist Hospital Yola

\begin{tabular}{|c|c|c|c|c|c|c|}
\hline \multirow[t]{2}{*}{ Pre-intervention } & \multicolumn{3}{|c|}{ Post-intervention } & \multirow[t]{2}{*}{$* \chi^{2}$} & \multirow[t]{2}{*}{ df } & \multirow[t]{2}{*}{ p-value } \\
\hline & optimal & Poor/Sub-optimal & Total & & & \\
\hline \multicolumn{7}{|l|}{ Group A } \\
\hline Optimal & $58(80.5)$ & $1(1.4)$ & $59(81.9)$ & \multirow[t]{3}{*}{6.750} & \multirow[t]{3}{*}{1} & \multirow[t]{3}{*}{0.009} \\
\hline Poor/Sub-optimal & $11(15.3)$ & $2(2.8)$ & $13(18.1)$ & & & \\
\hline Total & $69(95.8)$ & $3(4.2)$ & $72(100)$ & & & \\
\hline \multicolumn{7}{|l|}{ Group B } \\
\hline Optimal & $59(86.7)$ & $1(1.5)$ & $60(88.2)$ & \multirow[t]{3}{*}{0.800} & \multirow[t]{3}{*}{1} & \multirow[t]{3}{*}{0.371} \\
\hline Poor/Sub-optimal & $4(5.9)$ & $4(5.9)$ & $8(11.8)$ & & & \\
\hline Total & $63(92.6)$ & $5(7.4)$ & $68(100)$ & & & \\
\hline \multicolumn{7}{|l|}{ Group C } \\
\hline Optimal & $61(85.9)$ & $1(1.4)$ & $62(87.3)$ & \multirow[t]{3}{*}{0.250} & \multirow[t]{3}{*}{1} & \multirow[t]{3}{*}{0.617} \\
\hline Poor/Sub-optimal & $3(4.2)$ & $6(8.5)$ & $9(12.7)$ & & & \\
\hline Total & $63(90.1)$ & $7(9.9)$ & $71(100)$ & & & \\
\hline
\end{tabular}

*McNemar's Chi-square

The optimum adherence levels increased by $18.5 \%, 5.8 \%$, and $1.9 \%$, respectively, in groups $\mathrm{A}, \mathrm{B}$, and $\mathrm{C}$ at post-intervention. Alarm clocks as reminder tools alongside counselling had a significant effect on adherence than stickers, hand cards, and counselling alone. A ( $\mathrm{p}=0.009)$, $\mathrm{B}(\mathrm{p}=0.371) \mathrm{C}(\mathrm{p}=0.617)$. (Table 13). 
Table 14. Comparison of Adherence Level Between Groups A and B Post-intervention, Specialist Hospital Yola

\begin{tabular}{|l|l|l|}
\hline \multirow{2}{*}{ Adherence level } & Group A & Group B \\
\cline { 2 - 3 } & freq (\%) & freq (\%) \\
\hline Optimum & $70(97.2)$ & $59(86.8)$ \\
\hline Sub-optimum & $2(2.8)$ & $9(13.2)$ \\
\hline Poor & $0(0.0)$ & $0(0.0)$ \\
\hline Total & $72(100)$ & $68(100)$ \\
\hline
\end{tabular}

$\mathrm{G}^{2}=4.120 ; \mathrm{df}=1 ; \mathrm{p}=0.042$

A majority of respondents, $97.2 \%$ and $86.8 \%$ in groups $\mathrm{A}$ and $\mathrm{B}$ respectively, had optimum adherence, while respondents who had suboptimum adherence were $2.8 \%$ and $13.2 \%$, respectively in groups $\mathrm{A}$ and $\mathrm{B}$. Patients who had alarm clock as reminder tools alongside counselling were more likely to have optimal adherence compared with patients who had hand cards and stickers as reminder tools $(\mathrm{p}=0.042)$ (Table 14).

Table 15. Comparison of Adherence Level between Groups A and C Pre- and Post-intervention, Specialist Hospital Yola

\begin{tabular}{|l|l|l|l|l|}
\hline \multirow{2}{*}{ Adherence Level } & \multicolumn{2}{|l|}{ Pre-Group } & \multicolumn{2}{l|}{ Post-Group } \\
\cline { 2 - 5 } & Group A & Group C & Group A & Group C \\
\hline Optimum & $59(78.7)$ & $63(84.0)$ & $70(97.2)$ & $61(85.9)$ \\
\hline Suboptimum & $13(17.3)$ & $7(9.3)$ & $2(2.8)$ & $9(12.7)$ \\
\hline Poor & $3(4.0)$ & $5(6.7)$ & $0(0.0)$ & $1(1.4)$ \\
\hline Total & $75(100)$ & $75(100)$ & $72(100)$ & $71(100)$ \\
\hline
\end{tabular}

$\mathrm{G}^{2}=2.465 ; \mathrm{df}=2 ; \mathrm{p}=0.292 \mathrm{G}^{2}=6.816 ; \mathrm{df}=2 ; \mathrm{p}=0.033$

The optimum adherence increased from $78.7 \%$ and $84.0 \%$ pre-intervention to $97.2 \%$ and $85.9 \%$ post-intervention in groups $\mathrm{A}$ and $\mathrm{C}$, respectively. Those who had alarm clock with counselling were more likely to have optimum adherence than those with counselling alone $(\mathrm{p}=0.033)$. (Table 15).

Table 16. Comparison of Adherence Level between Groups B and C Pre- and Post-intervention, Specialist Hospital Yola

\begin{tabular}{|l|l|l|l|l|}
\hline \multirow{2}{*}{ Adherence Level } & \multicolumn{2}{|l|}{ Pre-Group } & \multicolumn{2}{l|}{ Post-Group } \\
\cline { 2 - 5 } & Group B & Group C & Group B & Group C \\
\hline Optimum & $60(80.0)$ & $63(84.0)$ & $59(86.8)$ & $61(85.9)$ \\
\hline Sub-optimum & $11(14.7)$ & $7(9.3)$ & $9(13.2)$ & $9(12.7)$ \\
\hline Poor & $4(5.3)$ & $5(6.7)$ & $0(0.0)$ & $1(1.4)$ \\
\hline Total & $75(100)$ & $75(100)$ & $68(100)$ & $71(100)$ \\
\hline
\end{tabular}

$\mathrm{G}^{2}=1.081 ; \mathrm{df}=2 ; \mathrm{p}=0.582 \mathrm{G}^{2}=1.355 ; \mathrm{df}=1 ; \mathrm{p}=0.508$

The optimum adherence increased from $80.0 \%$ and $84.0 \%$ pre-intervention to $86.8 \%$ and $85.9 \%$ post-intervention in groups B and C, respectively. There was no significant difference in adherence level between those who had stickers and reminder cards with counselling and those that had counselling alone post-intervention $(\mathrm{p}=0.508)$. (Table 16)

\section{Discussion}

The mean age of the respondents in the study was $35.9 \pm 9.7$ years. About $33.3 \%$ of them were 
between 30-39 years of age in all three groups. This finding was similar to studies done in Jos, Enugu, and Port-Harcourt on adherence among PLWHA, where the mean ages were found to be similar to this present study [7, 22, 24]. This showed that this age group was the most affected by HIV/AIDS in the studied population, which was similar to that found in the general population within the country [25].

The sex distribution in the study showed similar proportions of females in all three groups, with more females than males in each group. This is similar to a study on adherence among 213 HIV-infected patients in Ilorin, Nigeria, where the majority of respondents were females [26]. This probably could be due to the lower socio-economic status of females, which predisposes them to HIV infections.

There were about one-third of married respondents in each of the groups, with more than half of the total respondents being married. This is similar to the study on adherence in Enugu, Nigeria, in which more of the respondents were married [7]. This study became relevant considering the fact that heterosexual transmission accounts for the majority (80\%) of HIV infections in developing countries [27]. In this study, the proportion of respondents who had secondary education was about one-third in each group, with more than half of the total respondents having either secondary or tertiary education. This showed that the literacy level was high in the population studied.

The optimum adherence levels at preintervention in groups A (alarm clock), B (sticker, reminder card), and $\mathrm{C}$ (control) were $78.7 \%, 80.0 \%$, and $84.0 \%$, respectively. This finding was similar to that of a prospective study done in 2006 on adherence on 131 respondents in Jos, where adherence level was found to be $85.1 \%$ [21]. It was also similar to a study done in China in 2006 among 181 respondents to assess ARV adherence, where optimum adherence was found to be $81.8 \%$ [28]. These two studies in Jos and China were done in 2006; with recent emphases on adherence, these adherence levels may have changed with the passage of time.

A meta-analysis of African studies on ARV adherence showed an adherence level of $77 \%$ [29]. This meta-analysis showed that the adherence level in this present study is comparable with other countries in Africa and beyond and that adherence to ARV drugs is a problem in most African countries. In an interventional study to assess the effect of the cost of ARV drugs on adherence done in India, $84.7 \%$ of the respondents reported optimum adherence using self-reported assessment over a three-day period [30]. This high level of adherence though lower than what is expected, has brought to light that cost reduction alone could not improve adherence indicating that other interventions such as the use of reminder tools would be necessary. This was, however, higher than values of $64.0 \%$ and $62.2 \%$ reported by self-assessment in prospective studies done among PLWHA in Brazil and Togo, respectively [31, 32]. The major reason given for this low adherence was forgetfulness. This showed that adherence level could be improved by any means that can remind PLWHA of taking their drugs

The side effects of the ARV drugs were found to be associated with drug adherence levels in all three groups. Respondents with side effects were found to have less adherence level. This finding was consistent with studies done in Lagos and Benin to assess adherence among PLWHA, which showed side effects to be associated with decreasing adherence levels [33,34]. Once a patient develops side effects, it gives the person phobia for further intake of the drug leading to poor adherence. In this study, two-thirds of respondents were on 2 pills per dose in all the groups. This is a more convenient dose for respondents due to the low pill burden. Therefore, the number of pills per dose was not associated with adherence level in this study. This finding was inconsistent with studies done in Benin and Lagos among 
PLWHA on ART which showed an association between non-adherence and pill burden, with a higher number of pills leading to less adherence $[33,34]$. The association of adherence with the number of pills in these studies was because a majority of the respondents were on 5-7 pills per dose.

Forgetfulness was the commonest reason given for missed doses by respondents. Other reasons for missed doses were abnormal feeling/ side effects and feeling better. This finding was similar to a study done in Denmark among HIV patients who had been on medication for not less than 6 months, where most of them reported not remembering as the reason for missed doses [35]. It was also similar to a prospective study among HIV-infected respondents in Jos, where one of the main reasons given for missed doses was forgetfulness [22]. People living with HIV/AIDS have to take their drugs throughout their lives; challenges at the places of work and at home make PLWHA busy; therefore, there is the tendency to forget taking their drugs. The use of reminder tools could help them consistently take their drugs.

The groups that had alarm clock with counselling (group A) and those that had sticker and reminder card with counselling (group B) had optimum adherence of (78.7\%) and $(80.0 \%)$ respectively, pre-intervention. Postintervention, these proportions in groups $\mathrm{A}$ and B increased to $97.2 \%$ and $86.8 \%$, respectively. The difference was found to be statistically significant (0.042). This showed that the alarm clock had a greater effect on adherence than reminder cards and stickers. Although stickers and hand cards improved adherence, the improvement was not statistically significant. The findings of the study were similar to the findings of studies in Harlem, New York, and Mombasa in Kenya, where alarm devices were used to improve adherence to medication among adults and women respectively on ARV medication [12, 13]. The alarm on clocks reminded respondents on time to take their drugs which help to increase their ARV adherence level. The alarm clock has both visual and auditory effects on adherence than the sticker and reminder card that have only visual reminder effect. This could be responsible for the significant change in optimum adherence level.

The optimum adherence level before and after the intervention within groups increased by $15.3 \%$ in those that had alarm clock with counselling $(p=0.009)$ and by $5.9 \%$ among those that had stickers, reminder hand cards with counselling ( $\mathrm{p}=0.371)$, while among those that had counselling alone it increased by $4.2 \%$ $(p=0.617)$. The finding of the study was similar to the findings of studies in Harlem and Mombasa in Kenya, where alarm devices were used to improve adherence to ARV medication $[32,33]$. This finding, however, contrasted with those of a study done in Thai, South East Asia among children living with HIV/AIDS on ART where low-cost tools such as sticker and diary were found to improve ARV adherence [36]. In this present study, the improvement on adherence by sticker and reminder card was not statistically significant, probably due to the manner in which the stickers were used whereby they were placed in private places in order to prevent stigma, thus lowering the effectiveness of the tools.

\section{Conclusion}

The study found that ARV adherence was grossly sub-optimal pre-intervention, and reminder tools were found quite effective in improving ARV adherence post-intervention. Also, factors influencing ARV adherence have been clearly highlighted by this study and included the prevalence of drug side effects and forgetfulness. In comparing the various reminder tools tested, the alarm clock was more effective as a reminder tool for ARV adherence than a sticker and reminder cards.

Base on the findings of this study, the following recommendations are made: 
1) PLWHA should be counselled and educated on the use of alarm clock at home, which is cheap and available in most homes. The use of alarm on phone handsets should also be encouraged among PLWHA who have handsets.

2) Pharmaceutical companies should provide alarm clocks as part of ARV drug delivery packages to all patients.

3) The state government should constitute regular adherence monitoring and support teams at every antiretroviral centre all over

\section{References}

[1] Friendland, G. H., Williams, A 1999. Attaining higher goals in HIV treatment; the cultural importance of adherence. AIDS; Suppl 1: S61-72. PMID: 10546786.

[2] WHO, 2004 Award Million Dollar Contract for Global Treatment Preparedness Activities WHO New Release, www.who.millon.litmlan.

[3] WHO/UNIADS/Global Fund /US Government, $2005 . \quad$ Joint Media, www.theglobalfund.org/en/pressreleases/?pr=pr_050 126.

[4] Simon, J. M., Frick, P. A, Pantalone, D. W., Turner, B. J., 2003. Antiretroviral adherence intervention: a review of current literature and ongoing studies. Top HIV Medicine; 11:185-198.

[5] Dimetteo, M. R, Giordani, P. J., Lepper, H. S., Croghan, T. W., 2002. Patient adherence and medical treatment outcome: meta -analysis. Med Care; 40: 794-811.

[6] Pelella, F. I., Delaney, K. M., Moorman, A. C., Loveless, M. O., Fuhrer, J. Satten, G. A. et al 1998. Declining Morbidity and Mortality among Patients with Advanced HIV Infection. New England Journal of Medicine; 388:860.

[7] Uzochukwu, B. S., Onwujekwe, O. E., Onoka, A. C., Okoli, C., Uguru, N. P., Chukwuogo, O. I., 2009. Determinants of non-adherence to subsidized antiretroviral treatment in southeast Nigeria. Health Policy and Planning; 4(3): 189-196. the state. This would detect non-adherence early and appropriate measures are taken.

\section{Conflict of Interest}

The authors declared no conflict of interest in this study

\section{Acknowledgement}

The authors wish to appreciate the authority and the ART unit of the Specialist Hospital, Yola. We also acknowledge all the members of the research team for their contribution to the success of the study.

[8] Tuldra, A., Fumas, C. R., Ferrer, M. J., 2000. Prospective randomized two- arm control study to determine the efficacy of a specific intervention to improve long-term adherence to HAART. Journal of Acquire immune deficiency. Syndrome.; 22: 221228.

[9] Paterson, D. L, Swindells, S., Morhr, J., Brester, M., Vegis, F. N., Squier, L. et al 2000. Adherence to protease inhibitors therapy and outcomes in patients HIV infection. Annals of Internal Medicine;133: 2130 .

[10] Orell, C., Bangsberg, D. R., Baddri, M., Wood, R., 2003. Adherence is not a barrier to antiretroviral therapy in South Africa. AIDS; 17(9): 1369-1375. [11]Simon, J. M., Frick, P. A., Pantalone, D. W., Turner, B. J., 2003. Antiretroviral adherence intervention: a review of current literature and ongoing studies. Top HIV Medicine; 11:185-198.

[12]Frick, P. A., Lavry, L., Mandaliya, K., Kreis, J. K., 2001. Impact of an alarm device on medication compliance in women in Mombasa, Kenya. International Journal of STD AIDS;12(5): 329-333. [13] Mannhermer, G., Hirsch, Y., el-Sadr, W., 1998. The impact of the ALR alarm device on antiretroviral adherence among HIV-infected outpatient in Harlem. 12th World AIDS Conference. Geneva, Switzerland, [abstract 32325].

[14]Laster, S. F., Martin, J. L., Fleming, J. B., 1996. The effect of a medication alarm device on patient compliance with topical pilocarpine. Journal of American Optometric Association ;67: 654-658. 
[15]Ritchie, S., Scanlon, N., Lewis, M., Black, P., 2004. Use of a preprinted sticker to improve the prescribing of prophylactic antibiotics for hip fracture surgery. Quality and Safety in Health Care; 13(5): 384-387.

[16] Carrier, M. P., Leport, C., Protopopescu, C., Cassuto, J. P., 2006. Bouvet E. Factors associated with non-adherence to highly active antiretroviral therapy. Journal of Acquire. Immune. Deficiency Syndrome; 41(4): 477-485.

[17] National Bureau of Statistics, 2006. Federal Republic of Nigeria; 2006 Population Census., www.nigerianstat.gov.ng.

[18] Travelmath. Where is Yola, Nigeria? 2021.: www.travelmath.com/city/Yola+Nigeria.

[19] Institute of Human Virology of Nigeria. Your daily support hand card. IHVM Abuja, Nigeria.

[20] Abramson, J. T., Gahlinger, P, M., WINPEPE (PEPE-for-Windows): Computer programmes for epidemiologist. Available at: en.epiperspectves.com. content.

[21] Abah, I. O., Falang, K., Finangwai, A., Iyaji, P., Wakdet, L., Agbaji, O., et al 2006. Adherence to Antiretroviral Therapy in HIV-Infected Adults in Jos, Nigeria. AIDS, www.iasociety.org/.

[22] Kunutsor, S., Waaley, J., Muchun, S., Katabiri, E., Balidawa, H., Namagala, E., 2012. Improving adherence to antiretroviral therapy in sub- Saharan Africa HIV positive population: An enhance adherence package. AIDS Care.;24(10):1308-15., https//; www.tandfontline.com.

[23]Benner, J. S., Glynn, R. J., Mogur, H., Neumann, P. J., Weinstein, M. C., Avon, J., 2002. Long-term persistent in use of static therapy in elderly patients. JAMA; 288: 455-61.

[24] Chijioke, A. N., Osaro, E. O., Adebayo, E., Chris, I. A., 2006. Adherence to antiretroviral therapy among HIV-infected subjects in a resource limited setting in the Niger Delta of Nigeria. African Journal of Health Science; 13(3-4): 7-13.

[25]Bello, S. I., 2011. HIV/AIDS Patients Adherence to Antiretroviral Therapy in Sobi Specialist Hospital, Ilorin, Nigeria. Global Journal of Medical Research; 11(2): pp 17-25.

[26] Federal Ministry of Health (Nigeria), 2011. National HIV seroprevalence sentinel survey (HSS)
2010; National HIV/STI Control Programme, FMOH, Abuja. p16.

[27] Afolabi, M. O., Ijadunola, K. T., Fatusi, A. O., Olasode, O. A., 2009. Determinants of adherence to antiretroviral drugs among people living with HIV/AIDS in the Ife-Ijesa zone of Osun state, Nigeria. African Journal of Primary Health Care Family Medicine ;1(1): 1-6.

[28] Xiaoqi, W., Wu, Z., 2007. Factors associated with adherence to antiretroviral therapy among HIV/AIDS patients in rural China. AIDS; 21 (suppl. 8): 149-155.

[29]Chi, B. H., Cantrel, R. A., Zulu, J., Mulenga, B. L., Levy, J. W., Tambatamba, B. C. et al 2009. Adherence to first line antiretroviral therapy effect son non-virologic outcomes among patients on treatment for more than 12 months in Luksaka, Zambia. International. Journal of. Epidemiology; 38(3): 746-756.

[30] Singh, N., Squer, C., Haye, S., 1994 Determinants of compliance in patients with HIV: prospective assessment with implication for enhancing compliance. $34^{\text {th }}$ interscience conference on antimicrobial agents and chemotherapy. Orland, jia.sagepubcom/content/9/3/191.

[31] Yao, P., Kpatcha, T., Agnon, B., Vincent, P. P., Innocent, P. G., Etienne, K. K., 2010. Knowledge and adherence to antiretroviral therapy among adult people living with HIV/AIDS treated in health care centers of the association "Espoir Vie Togo" in Togo, West Africa. BMC Clinical Pharmacology;10(11): 1-7.

[32] Garcia, R., Badaro, R., Netto, N. E., Silva, N., Amoria, S. E, Ramos, A. et al 2006. Cross Sectional Study to Evaluate Factors Associated with Adherence to Antiretroviral Therapy by Brazilian HIV Infected Patients. AIDS Research and Human Antiretroviruses; 22 (12): 1248-1252.

[33]Erah, O. P., Arute, J. E., 2008. Adherence of HIV/AIDS Patients to Antiretroviral Therapy in a Tertiary Health Facility in Benin City. African Journal of Pharmacy and Pharmacology; 2(7): 14552.

[34] Adeyemi, A. O., Olaogun, O. O., Adesola, A. O., 2008. Challenges to Adherence among HIVPositive Patients on Antiretroviral Therapy in Lagos, 
Nigeria. Journal of the International AIDS Society; 11(Suppl 1): 172.

[35] Gifford, A. L., Borman, J. E., Shirverly, M. J., Wright, B. C., Richman, D. D., Bozzette, S. A., 2000. Predictor of self-reported adherence and plasma HIV concentration in patients on multi-drug antiretroviral regimens. Journal of Acquired Immune
Deficiency Syndrome; 23(5): 386-395.

[36] Siripong, A., Pancharoen, C., Chuamchaitrakool, A., Apateerapong, W., Ruxrungtham, K., Phanuphak, P. et al 2004. Improving adherence to ARV in Thai children using low-cost tools focusing on positive reinforcement. Int Conf AIDS. 11-16;15: 5779-5784. 